This item was submitted to Loughborough's Research Repository by the author.

Items in Figshare are protected by copyright, with all rights reserved, unless otherwise indicated.

\title{
Blunted sweating does not alter the rise in core temperature in people with multiple sclerosis exercising in the heat
}

\section{PLEASE CITE THE PUBLISHED VERSION}

https://doi.org/10.1152/ajpregu.00090.2020

\section{PUBLISHER}

American Physiological Society

\section{VERSION}

AM (Accepted Manuscript)

\section{PUBLISHER STATEMENT}

This paper was accepted for publication in the journal American Journal of Physiology-Regulatory, Integrative and Comparative Physiology and the definitive published version is available at https://doi.org/10.1152/ajpregu.00090.2020

\section{LICENCE}

CC BY-NC-ND 4.0

\section{REPOSITORY RECORD}

Chaseling, Georgia K, Davide Filingeri, Dustin R Allen, Michael Barnett, Steve Vucic, Scott L Davis, and Ollie Jay. 2020. "Blunted Sweating Does Not Alter the Rise in Core Temperature in People with Multiple Sclerosis Exercising in the Heat". Loughborough University. https://hdl.handle.net/2134/13373006.v1. 


\section{Blunted sweating does not alter the rise in core temperature in people with multiple sclerosis exercising in the heat}

Georgia K Chaseling ${ }^{1}$, Davide Filingeri ${ }^{1,2}$, Dustin Allen ${ }^{3,4}$, Michael Barnett ${ }^{5}$, Steve Vucic ${ }^{6}$, Scott L Davis ${ }^{3,7}$, Ollie Jay ${ }^{1,8} \bowtie$

${ }^{1}$ The University of Sydney, Thermal Ergonomics Laboratory, Sydney School of Health Sciences, Faculty of Medicine and Health, NSW, AUSTRALIA

${ }^{2}$ THERMOSENSELAB, Environmental Ergonomics Research Centre, Loughborough University, Leicestershire, UNITED KINGDOM

${ }^{3}$ Applied Physiology \& Wellness Southern Methodist University, Dallas, TX, UNITED STATES

${ }^{4}$ Boston University, Department of Health Sciences, Boston, MS, UNITED STATES

${ }^{5}$ The University of Sydney, Brain and Mind Centre, Camperdown, NSW, AUSTRALIA

${ }^{6}$ The University of Sydney Clinical School, Westmead Clinical School, Westmead, NSW, AUSTRALIA

${ }^{7}$ Neurology and Neurotherapeutics, University of Texas Southwestern Medical Center, Dallas, TX, UNITED STATES

${ }^{8}$ The University of Sydney, Charles Perkins Centre, Camperdown, NSW, AUSTRALIA

Running Head: Exercise and thermoregulation for people with MS

\footnotetext{
Address for correspondence:

Ollie Jay $\bowtie$

Thermal Ergonomics Laboratory, Sydney School of Health Sciences, Faculty of Medicine and Health, The University of Sydney, NSW, AUSTRALIA

Tel: +61 293519328

E-mail: ollie.jay@sydney.edu.au
} 
Abstract

40 Purpose: To determine whether thermoregulatory capacity is altered by MS during exercise 41 in the heat.

42 Methods: Sixteen MS (EDSS: $2.9 \pm 0.9 ; 47 \pm 8 \mathrm{y} ; 77.6 \pm 14.0 \mathrm{~kg}$ ) and 14 healthy (CON) control 43 participants $(43 \pm 11 \mathrm{y} ; 78.6 \pm 17.0 \mathrm{~kg})$ cycled at a heat production of $4 \mathrm{~W} \cdot \mathrm{kg}^{-1}$ for 60 minutes 44 at $30^{\circ} \mathrm{C}, 30 \% \mathrm{RH}$ (WARM). A subset of 8 MS (EDSS: $2.6 \pm 0.5 ; 44 \pm 8 \mathrm{y} ; 82.3 \pm 18.2 \mathrm{~kg}$ ) and 8 $45 \mathrm{CON}(44 \pm 12 \mathrm{y} ; 81.2 \pm 21.1 \mathrm{~kg})$ also exercised at $35^{\circ} \mathrm{C}, 30 \% \mathrm{RH}(\mathrm{HOT})$. Rectal $\left(T_{\mathrm{re}}\right)$, mean 46 skin $\left(T_{\mathrm{sk}}\right)$ temperature, and local sweat rate on the upper-back ( $\left.\mathrm{LSR}_{\text {back }}\right)$ and forearm $47\left(\mathrm{LSR}_{\mathrm{arm}}\right)$, were measured.

48 Results: All CON, yet only 9 of 16, and 7 of 8 MS participants completed 60 min of exercise 49 in WARM and HOT trials, respectively. All MS participants unable to complete exercise 50 stopped with $\Delta T_{\text {re }}$ between $0.2-0.5^{\circ} \mathrm{C}$. The time to reach a $\Delta T_{\text {re }}$ of $0.2^{\circ} \mathrm{C}$ was similar 51 (MS:28 $\pm 15 \mathrm{~min}, \mathrm{CON}: 32 \pm 18 \mathrm{~min} ; \mathrm{P}=0.51$ ). For MS participants completing 60-min of 52 exercise in WARM, $\Delta T_{\text {re }}(\mathrm{P}=0.13), \Delta T_{\text {sk }}(\mathrm{P}=0.45), \mathrm{LSR}_{\text {back }}(\mathrm{P}=0.69)$ and $\mathrm{LSR}_{\text {arm }}(\mathrm{P}=0.54)$ were similar to $\mathrm{CON}$, but $\Delta \mathrm{T}_{\mathrm{b}}\left(\mathrm{MS}: 0.16 \pm 0.13^{\circ} \mathrm{C}, \mathrm{CON}: 0.07 \pm 0.06^{\circ} \mathrm{C} ; \mathrm{P}=0.02\right)$ and onset time

54 (MS:16 $\pm 10 \mathrm{~min}, \mathrm{CON}: 8 \pm 5 \mathrm{~min} ; \mathrm{P}=0.02$ ) for sweating were greater. Similarly, in $\mathrm{HOT}, \Delta T_{\text {re }}$ $55(\mathrm{P}=0.52), \Delta T_{\text {sk }}(\mathrm{P}=0.06), \mathrm{LSR}_{\text {back }}(\mathrm{P}=0.59)$ and $\mathrm{LSR}_{\text {arm }}(\mathrm{P}=0.08)$ were similar, but $\Delta \mathrm{T}_{\mathrm{b}}(\mathrm{MS}$ : $\left.560.19 \pm 0.16^{\circ} \mathrm{C}, \mathrm{CON}: 0.06 \pm 0.04^{\circ} \mathrm{C} ; \mathrm{P}=0.04\right)$ and onset time (MS: $13 \pm 7 \mathrm{~min}, \mathrm{CON}: 6 \pm 3 \mathrm{~min}$; $57 \mathrm{P}=0.02$ ) for sweating were greater with MS.

58 Conclusion: Even at $35^{\circ} \mathrm{C}$, a delayed sweating onset didn't alter heat loss to sufficiently 59 affect exercise-induced rises in core temperature. Heat intolerance with MS does not seem 60 attributable to thermoregulatory impairments.

61 Keywords: Uhthoff's Phenomenon, autonomic dysfunction, heat sensitivity, 62 thermoregulation 
Multiple sclerosis (MS) is an autoimmune, inflammatory demyelinating disease of the central nervous system (CNS). Up to $80 \%$ of people with MS have an intolerance to the heat

66 (36), also known as Uhthoff's phenomenon (37), which describes a transient worsening of

67 MS symptoms with exposure to a hot environment and/or during physical activity. An 68 increase in core temperature from rest as small as 0.2 to $0.5^{\circ} \mathrm{C}$ has been reported to induce

69 Uhthoff's phenomenon, likely due to altered conduction in temperature sensitive neurons (14,

70 32). In some patients, this heat intolerance subsequently reduces the capacity to work and perform household tasks (35), and increases postural sway, which potentially leads to an increased risk of falling (30). Indeed, $\sim 30 \%$ of people with MS will leave their job, with an additional $\sim 40 \%$ admitting their job is at risk due to heat intolerance and associated symptoms (35).

A contributing factor to the rapid onset of heat intolerance may be a disproportionate rise in core temperature for a given metabolic heat load, by virtue of an impaired thermoregulatory response. A sufficient sweating and skin blood flow response is critical for regulating core body temperature during exercise and/or heat exposure. The onset of these effector responses and the rate at which sweat output and skin blood flow increases for a 80 given rise in body temperature dictates the rate at which heat is stored and distributed within 81 the body (26).

82 It has recently been reported that people with relapsing-remitting MS demonstrate a blunted sudomotor, but not vasomotor response, during moderate exercise at a fixed heat

84 production in a temperate $\left(25^{\circ} \mathrm{C}\right)$ environment (1). While this blunted sudomotor response

85 did not result in larger rises in core temperature compared to healthy controls (1), exercise in 86 hotter conditions that approach skin temperature (i.e. 30 to $35^{\circ} \mathrm{C}$ ) may elicit a net thermal 87 load that exceeds the thermoregulatory capacity of people with MS sufficiently to cause 
greater rises in body temperature for a given activity level. During passive heating in an encapsulated environment with a $48^{\circ} \mathrm{C}$ water perfused suit to a similar rise in core temperature $\left(0.8^{\circ} \mathrm{C}\right)$, Allen et al $(2)$ reported an average local sweat rate that is $0.24 \mathrm{mg} \cdot \mathrm{cm}^{-}$

$91^{2} \cdot \mathrm{min}^{-1}$ lower in people with MS relative to healthy control participants. If this difference in 92 sweating is extended across the entire body surface, the parallel difference in evaporative 93 potential in a non-encapsulated environment should be sufficient to elicit (assuming $50 \%$ 94 evaporation) up to a $\sim 0.8^{\circ} \mathrm{C}$ greater rise in core temperature in a 70 -kg MS participant after 95 60-min of exercise. Whether these observations translate directly to a hot non-encapsulated environment though, remains unknown.

To assess any differences in time-dependent changes in core temperature and sweating between MS and healthy populations, any differences in body size must be

99 accounted for in the experimental design. It has been recently demonstrated that prescribing 100 exercise intensity to elicit a fixed metabolic heat production per unit total body mass (i.e. $101 \mathrm{~W} \cdot \mathrm{kg}^{-1}$ ), irrespective of relative exercise intensity (i.e. percentage of maximum oxygen consumption; $\% \mathrm{VO}_{2} \max$ ) eliminates any systematic differences in the exercise-induced rise

103 of core temperature due to biophysical factors $(13,21)$. Similarly, if participant groups are 104 matched for body size, such an approach will also elicit a similar evaporative requirement for 105 heat balance $\left(\mathrm{E}_{\text {req }}\right)$ per unit surface area, which has been shown to determine steady-state 106 local sweat rates, again irrespective of $\% \mathrm{VO}_{2} \max (13)$.

107 The aims of this study were to assess whether, 1) people with MS demonstrate a 108 disproportionate rise in core temperature relative to healthy controls during moderate exercise 109 in a warm $\left(30^{\circ} \mathrm{C}, 30 \% \mathrm{RH}\right)$ and hot $\left(35^{\circ} \mathrm{C}, 30 \% \mathrm{RH}\right)$ environment due to impaired local 110 sweating; and 2) any impaired thermoregulatory response with MS will be sufficient to 111 reduce exercise tolerance in both warm and hot environments compared to age-matched 112 health controls. We hypothesized that 1) people with MS will demonstrate a greater rise in 
113 core temperature by virtue of a blunted sweat response in both the warm and hot

114 environments, and 2) the greater rise in core temperature in MS participants will decrease

115 exercise time to exhaustion at a fixed heat production in both the warm and hot environments

116 compared to age-matched healthy controls.

\section{Methods}

\section{Participants}

119 Sixteen relapsing-remitting MS patients and 14 control participants, with a similar age 120 and body size, were recruited to cycle in a $30^{\circ} \mathrm{C}, 30 \% \mathrm{RH}$ (WARM) environment (Table 1).

121 A subset of 8 relapsing-remitting MS participants and 8 control participants with a similar 122 age and body size completed the same exercise bout in a $35^{\circ} \mathrm{C}, 30 \% \mathrm{RH}$ (HOT) environment

123 (Table 1). For the WARM trials, 9 participants were required based on a power calculation

124 (Heinrich-Heine-Universität, Dusseldorf, Germany) using an $\alpha$ of 0.05 and a $\beta$ of 0.7 and an 125 effect size of 1.0 for the main outcome variable of differences in sweat rate in an 126 encapsulated heat stress environment between MS and CON participants (2). For the HOT

127 trials, a convenience sample was used with only $8 \mathrm{MS}$ and $8 \mathrm{CON}$ participants returning to 128 complete this trial. Eligible participants were free of any cardiovascular or metabolic 129 disorders and were not prescribed medication that contained a muscarinic antagonist agent. 130 MS participants were excluded if they had experienced a relapse six months prior to 131 commencing the study. Disease modifying treatments (DMT) used by MS participants in this 132 study were as follows: Tysabri (natalizumab), $n=4$; Copaxone (glatiramer acetate), $n=1$; 133 Avonex (interferon beta-1a), $n=1$; Tecfidera (dimethyl fumarate), $n=2$; Lemtrada 134 (alemtuzumab), $n=1$; Fampridine (fampyra), $n=1$; Lioresal (Baclofen), $n=1$; no DMT 135 reported, $n=5$. All participants were informed of any risks involved with the study and 136 provided their written informed consent. This study was approved by the University of 137 Sydney Human Research Ethics Committee (HREC: 2015/125). 
139 All trials were performed in the Thermal Ergonomics Laboratory at the University of 140 Sydney, Australia. All participants attended one preliminary trial, 8 MS and CON 141 participants completed two experimental trials (WARM and HOT), while 8 MS and 6 CON 142 participants completed one experimental trial (WARM ONLY). During the experimental 143 trials, participants cycled on a semi-recumbent ergometer at a fixed metabolic heat 144 production $\left(\mathrm{H}_{\text {prod }}\right)$ of $4 \mathrm{~W} \cdot \mathrm{kg}^{-1}$ for 60 minutes. Participants completed their trials in either a $14530^{\circ} \mathrm{C}, 30 \% \mathrm{RH}(16 \mathrm{MS}, 14 \mathrm{CON})$ or $35^{\circ} \mathrm{C}, 30 \% \mathrm{RH}(8 \mathrm{MS}, 8 \mathrm{CON})$ environment. All 146 participants were instructed to abstain from alcohol and avoided strenuous exercise up to $24 \mathrm{~h}$ 147 before their trial.

\section{Preliminary trial}

149 During the preliminary session, height and weight were recorded followed by a 150 submaximal aerobic test on a semi-recumbent cycle ergometer. A submaximal test was used 151 to determine the relationship between external work rate and oxygen consumption $\left(\mathrm{VO}_{2}\right)$ and 152 thus $\mathrm{H}_{\text {prod }}(12)$. The submaximal test protocol started with a 5-min warm-up period followed 153 by 5 -min of rest, after which the participant was fitted with a face mask attached to a 154 metabolic cart. Participants began cycling at a resistance of $20 \mathrm{~W}$ below the predicted 155 workload to elicit an individualized $\mathrm{H}_{\text {prod }}$ of $4 \mathrm{~W} \cdot \mathrm{kg}^{-1}$, at a cadence of $60 \mathrm{rpm}$. The external 156 workload of the bike was then increased by $20 \mathrm{~W}$ every three minutes for 4 separate stages or 157 until volitional exhaustion (25). A least square regression equation was employed using 158 submaximal HR and oxygen consumption at the end of each stage and extrapolated to the 159 maximal age-predicted $\mathrm{HR}\left(220\right.$ - age) (5) to determine $\mathrm{VO}_{2 \max }$ using the Young Men's

160 Christian Association (YMCA) protocol (16).

161 Experimental trials 
162 During each experimental trial, participants cycled on a semi-recumbent ergometer 163 for 60 minutes in a climate chamber regulated at $30^{\circ} \mathrm{C}, 30 \% \mathrm{RH}(\mathrm{WARM})$ or $35^{\circ} \mathrm{C}, 30 \% \mathrm{RH}$

164 (HOT). Participants were instrumented, and baseline data was collected for 15 minutes, after

165 which they began to cycle at a $\mathrm{H}_{\text {prod }}$ of $4 \mathrm{~W} \cdot \mathrm{kg}^{-1}$. At the cessation of exercise, ambient 166 temperature was decreased to $20^{\circ} \mathrm{C}, 30 \% \mathrm{RH}$ and participants sat quietly during a 30-minute 167 recovery period.

Instrumentation

169 Partitional calorimetry: Breath-by-breath metabolic energy expenditure $(M)$ was 170 calculated using indirect calorimetry via a metabolic cart (Quark CPET, Cosmed, Asia 171 Pacific PTY, NSW, Australia). Minute-averaged values were calculated using the following 172 equation (28):

$$
M=\mathrm{VO}_{2} \cdot \frac{\left(\left(\frac{R E R-0.7}{0.3}\right) \cdot E c\right)+\left(\left(\frac{1-R E R}{0.3}\right) \cdot E f\right)}{60} \cdot 1000[\mathrm{~W}]
$$

174 Where: $\mathrm{VO}_{2}$ is the rate of oxygen consumption $\left(\mathrm{L} \cdot \mathrm{min}^{-1}\right)$; RER is the respiratory 175 exchange ratio; Ec and Ef are the energetic equivalents of carbohydrate $\left(21.13 \mathrm{~kJ} \cdot \mathrm{L}^{-1}\right.$ of $\left.\mathrm{O}_{2}\right)$ 176 and fat $\left(19.62 \mathrm{~kJ} \cdot \mathrm{L}^{-1}\right.$ of $\left.\mathrm{O}_{2}\right)$ respectively. External workload was regulated using a semi177 recumbent cycle ergometer (Corival Recumbent, Lode B.V., Groningen, Netherlands). The 178 rate of heat production $\left(\mathrm{H}_{\text {prod }}\right)$ was subsequently calculated as the difference between $M$ and 179 external workload (W) and then converted into $\mathrm{W} \cdot \mathrm{kg}^{-1}$ by dividing by total body mass.

180 The evaporative requirement $\left(\mathrm{E}_{\text {req }}\right)$ for heat loss was determined as described by 181 Cramer and Jay (12) and expressed as $\mathrm{W} \cdot \mathrm{m}^{-2}$.

182 Core Temperature: Rectal $\left(T_{\text {re }}\right)$ temperature was measured using general-purpose 183 paediatric thermistor (TM400, Covidien, Massachusetts, USA) self-inserted to a depth of $\sim 15$ 184 cm past the anal sphincter (23).

185 Skin Temperature: was measured at four sites across the left side of the body using T186 type thermocouples (Concept Engineering, Connecticut, USA), secured to the skin using 
187 surgical tape. Mean skin temperature $\left(T_{\text {sk }}\right)$ was expressed as a weighted average in 188 accordance with Ramanathan (31): chest $30 \%$, shoulder $30 \%$, thigh $20 \%$, and calf $20 \%$. All 189 thermometric measurements were sampled every 5 seconds (NI cDAQ-91722 module,

190 National Instruments, Texas, USA) and displayed in real-time using LabView (v7.0, National 191 Instruments).

192 Local sweat rates (LSR): were measured using $4.1-\mathrm{cm}^{2}$ ventilated sweat capsules, 193 secured to the skin using surgical tape (Transpore ${ }^{\circledR}, 3 \mathrm{M}$, Ontario, Canada). Capsules were 194 placed on the left upper back $\sim 5 \mathrm{~cm}$ above the scapular spine over the trapezium and mid195 forearm $\sim 5 \mathrm{~cm}$ distal to the antecubital fossa. Anhydrous air was passed through each capsule 196 at a constant flow rate of $750 \mathrm{~mL} \cdot \mathrm{min}^{-1}$ (Omega FMA-A2307, Omega Engineering, 197 Connecticut, USA) and the temperature and humidity of outflowing air were measured every 1985 s using factory-calibrated capacitance hygrometers (HMT333, Vaisala, Vantaa, Finland).

199 LSR measures were calculated as the product of change in absolute humidity across the 200 capsule and flow rate and expressed relative to the area under the capsule in $\mathrm{mg} \cdot \mathrm{cm}^{-2} \cdot \mathrm{min}^{-1}$.

201 Electrocardiograph: A wireless 6-lead ECG system recorded measures of heart rate 202 (Quark ECG stress system, Cosmed, NSW, Australia).

203 Thermoeffector responses: LSR onset thresholds and thermosensitivity of the forearm 204 and upper back were determined as a function of meant body temperature $\left(T_{\mathrm{b}}\right)$. It is well 205 established that core temperature has approximately a nine to ten times greater the influence 206 on thermoeffector responses than skin temperature $(18,27)$. Therefore, $T_{\mathrm{b}}$ was calculated 207 using a weighting of $0.9 \times T_{\mathrm{re}}$ and $0.1 \times T_{\mathrm{sk}}$ and $\Delta T_{\mathrm{b}}$ was calculated as the 30 -sec average 208 change from baseline. Thermosensitivities for each participant were determined separately 209 for LSR of the forearm and back, using a simple linear regression for the period of linear 210 increase in LSR plotted against the $\Delta T_{\mathrm{b}}$.

\section{Statistical Analysis}



and HOT experimental trials, an independent-samples two-tailed t-test was used to compare

214 absolute baseline and changes from baseline of $T_{\mathrm{re}}, T_{\mathrm{sk}}$ at the $30^{\text {th }}$ and $60^{\text {th }}$ minute of exercise

215 and absolute measures of HR, LSR at the forearm and upper back at the $30^{\text {th }}$ and $60^{\text {th }}$ minute 216 of exercise between the MS and CON groups. Furthermore, an independent-samples two-

217 tailed t-test was used to compare the time taken (in minutes) to reach a rise in $T_{\text {re }}$ of $0.2^{\circ} \mathrm{C}$

218 between the MS and CON groups and the evaporative requirement of heat loss. Workload 219 was determined by averaging work in watts $(\mathrm{W}), \mathrm{W} \cdot \mathrm{m}^{-2}$ and $\mathrm{W} \cdot \mathrm{kg}^{-1}$ from the tenth minute of exercise until the end of the trial for each individual participant. An independent-samples two-tailed t-test was then used to assess the difference between MS and CON groups. An independent-samples two-tailed t-test was then used to assess $\Delta T_{\mathrm{b}}$ onset thresholds, time at response of onset, and thermosensitivity of LSR on the forearm and upper back.

224 Thermosensitivities for each participant were determined separately for LSR of the forearm and back, using a simple linear regression for the period of linear increase in LSR plotted against the $\Delta T_{\mathrm{b}}$. The level of significance for all analyses employed an $\alpha$ of 0.05 . All multiple comparison p-values were adjusted using a Bonferroni correction. Statistical analyses were performed, and all data were graphed using GraphPad Prism (Version 7 La Jolla, CA, USA).

\section{Results}

Sample sizes for statistical analyses reflect the number of MS patients that completed

23130 and 60 min of exercise, respectively, in the WARM and HOT trials. Absolute rectal 232 temperature, heart rate and the absolute and relative workloads for both the WARM and HOT 233 trials were not different between the MS and CON groups (Table 1). Furthermore, the 234 evaporative requirement for heat loss was similar between the MS and CON groups for both 235 the WARM and HOT trials (Table 1).

\section{Exercise tolerance}


WARM Trial: All control participants were able to complete $60 \mathrm{~min}$ of exercise.

238 However, it was observed that 14 out of 16 and 9 out of 16 MS participants were able to complete 30 and $60 \mathrm{~min}$ of exercise, respectively. MS participants who were unable to sustain $60 \mathrm{~min}$ of cycling, exercised for $33 \pm 11 \mathrm{~min}$ (range: $15-45 \mathrm{~min}$ ) before volitional 241 exhaustion.

HOT Trial: All control participants were able to complete $60 \mathrm{~min}$ of exercise. However, it was observed that 7 out of 8 MS participants were able to complete exercise for

$24460 \mathrm{~min}$, the remaining 1 participant completed $20 \mathrm{~min}$ of exercise before volitional exhaustion.

Core and skin temperatures

$\underline{\text { WARM Trial: }}$ The change in $T_{\text {re }}$ after $30 \min (\mathrm{MS}:-n=14 ; \mathrm{CON}: n=14 ; \mathrm{P}=0.75)$ and $60 \min$ of exercise (MS: $n=9 ; \mathrm{CON}: n=14 ; \mathrm{P}=0.13$ ) were not different between groups (Figure 1A). The change in $T_{\text {sk }}$ following $30 \min (\mathrm{MS}: n=14 ; \mathrm{CON}: n=14 ; \mathrm{P}=0.13$ ) and 60 min of exercise (MS: $n=9 ; \mathrm{CON}: n=14 ; \mathrm{P}=0.30$ ) were not different between groups (Figure 1B). The time taken to reach a rise in $T_{\text {re }}$ of $0.2^{\circ} \mathrm{C}$, often considered as lower limit of Uhthoff's threshold, (Figure 1C) was not different between MS and CON groups (P = 0.51). The end of exercise change in $T_{\mathrm{re}}$ for the MS and CON groups are displayed in figure 1D-E. For all MS participants who were unable to complete 60 min of exercise, the end of exercise change in $T_{\text {re }}$ was within the $0.2-0.5^{\circ} \mathrm{C}$ Uhthoff's phenomenon threshold except for one participant who stopped exercise after 15 minutes with a rise in $T_{\text {re }}$ of $0.10^{\circ} \mathrm{C}$.

HOT Trial: The change in $T_{\text {re }}$ after $30 \min (\mathrm{MS}: n=7 ; \mathrm{CON}: n=8 ; \mathrm{P}=0.48)$ and 60 min of exercise (MS: $n=7$; CON: $n=8 ; \mathrm{P}=0.65$ ) were again not different between groups (Figure 2A). The change in $T_{\mathrm{sk}}$ following $30 \min (\mathrm{MS}: n=7 ; \mathrm{CON}: n=8 ; \mathrm{P}=0.14$ ) and 60 min of exercise (MS: $n=7$; CON: $n=8 ; \mathrm{P}=0.06$ ) was not statistically different (Figure $2 \mathrm{~B}$ ).

261 The time taken to reach a rise in $T_{\text {re }}$ of $0.2^{\circ} \mathrm{C}$ (Figure 2C) was not different between the MS 
and CON participants $(\mathrm{P}=0.19)$. The end of exercise change in $\mathrm{T}_{\mathrm{re}}$ for the MS and CON

groups are displayed in figure 2D-E. For the MS participant who was unable to complete 60

min of cycling, the end change in $\mathrm{T}_{\mathrm{re}}$ was within the $0.2-0.5^{\circ} \mathrm{C}$ threshold of Uhthoff's

phenomenon.

266

267

268

269

270

271

272

273

274

275

\section{Sweat rates and onset thresholds}

WARM Trial: Data for upper back local sweat rate was not obtained for $1 \mathrm{MS}$ participant. Local sweat rates of the upper back after $30 \mathrm{~min}(\mathrm{P}=0.19)$ and $60 \mathrm{~min}$ of exercise $(P=0.69)$ were not different between groups (Table 2). Similarly, local sweat rates of the forearm after $30 \mathrm{~min}(\mathrm{P}=0.19)$ and $60 \mathrm{~min}$ of exercise $(\mathrm{P}=0.54)$ were not different between groups (Table 2). The change in mean body temperature onset threshold for the forearm and upper back LSR and the subsequent thermosensitivity are displayed in Figure 3. Onset and thermosensitivity calculations for local sweat rate were performed on 15 and 14 MS participants for the forearm and upper back local sweat rate respectively and 13 CON participants for the forearm and upper back because either no sweat rate data was collected ( $n$ $=1$ ) or we were unable to define the period of linear increase in LSR plotted against the $\Delta T_{\mathrm{b}}$. The change in mean body temperature for the onset of forearm sweating was greater $(\mathrm{P}=$ 0.04) in the MS compared to the CON group but this difference was not observed for upper back sweating $(\mathrm{P}=0.27)$. The time at onset was greater in the MS group for forearm (MS: 15 $\pm 10 \mathrm{~min}$; $\mathrm{CON}: 8 \pm 5 \mathrm{~min} ; \mathrm{P}=0.03$ ) but not the upper back (MS: $14 \pm 12 \mathrm{~min}$; CON: $10 \pm 9$ $\min ; \mathrm{P}=0.26$ ). The thermosensitivity was not different between groups for either the forearm (MS: $0.76 \pm 0.72 \mathrm{mg} \cdot \mathrm{min}^{-1} \cdot \mathrm{cm}^{-2} \cdot{ }^{\circ} \mathrm{C} ; \mathrm{CON}: 1.18 \pm 0.59 \mathrm{mg} \cdot \mathrm{min}^{-1} \cdot \mathrm{cm}^{-2} \cdot{ }^{\circ} \mathrm{C} ; \mathrm{P}=0.34$ ) or the upper back (MS: $0.78 \pm 0.77 \mathrm{mg} \cdot \mathrm{min}^{-1} \cdot \mathrm{cm}^{-2} \cdot{ }^{\circ} \mathrm{C} ; \mathrm{CON}: 1.23 \pm 0.85 \mathrm{mg} \cdot \mathrm{min}^{-1} \cdot \mathrm{cm}^{-2} \cdot{ }^{\circ} \mathrm{C} ; \mathrm{P}=$ $0.34)$.

HOT Trial: Local sweat rates for the upper back and forearm were not obtained for one participant, and another had an exercise time under $30 \mathrm{~min}$, therefore, data were analysed 
287 for 6 out of $8 \mathrm{MS}$ participants. Local sweat rates of the upper back after $30 \mathrm{~min}(\mathrm{P}=0.78)$

288 and 60 min of exercise $(\mathrm{P}=0.59)$ were not different between groups (Table 2). Similarly, 289 local sweat rates of the forearm after $30 \mathrm{~min}(\mathrm{P}=0.06)$ and $60 \mathrm{~min}$ of exercise $(\mathrm{P}=0.08)$

290 were not different between groups (Table 2). The change in mean body temperature onset

291 threshold for the forearm and upper back LSR and the subsequent thermosensitivity are

292 displayed in Figure 3. Onset and thermosensitivity calculations for local sweat rate were

293 performed on 7 out of 8 MS participants for both the forearm and upper back local sweat rate

294 because local sweat rate data was not collected on 1 participant. The change in mean body

295 temperature for the onset of forearm sweating was greater $(\mathrm{P}=0.04)$ in the MS compared to

296 the CON group but this difference was not observed for upper back sweating $(\mathrm{P}=0.12)$. The

297 time at onset was greater in the MS group for forearm (MS: $13 \pm 7 \mathrm{~min}$; CON: $6 \pm 3 \mathrm{~min}$; $\mathrm{P}=$

298 0.02) but not the upper back (MS: $10 \pm 7 \mathrm{~min}$; CON: $7 \pm 4 \mathrm{~min} ; \mathrm{P}=0.29$ ). The

299 thermosensitivity were not different between groups for either the forearm (MS: $1.01 \pm 0.43$

$300 \mathrm{mg} \cdot \mathrm{min}^{-1} \cdot \mathrm{cm}^{-2} \cdot{ }^{\circ} \mathrm{C} ; \mathrm{CON}: 1.59 \pm 1.24 \mathrm{mg} \cdot \mathrm{min}^{-1} \cdot \mathrm{cm}^{-2} \cdot{ }^{\circ} \mathrm{C} ; \mathrm{P}=0.26$ ) or the upper back (MS:

$\left.301 \quad 1.37 \pm 1.66 \mathrm{mg} \cdot \mathrm{min}^{-1} \cdot \mathrm{cm}^{-2} \cdot{ }^{\circ} \mathrm{C} ; \mathrm{CON}: 1.06 \pm 0.69 \mathrm{mg} \cdot \mathrm{min}^{-1} \cdot \mathrm{cm}^{-2} \cdot{ }^{\circ} \mathrm{C} ; \mathrm{P}=0.63\right)$.

302 Heart rate

$303 \quad 30^{\circ} \mathrm{C}$ trial: Heart rate was not different between groups after 30 min (MS: $99 \pm 14$

304 bpm, $n=14 ; \mathrm{CON}: 106 \pm 26 \mathrm{bpm}, n=14 ; \mathrm{P}=037)$ and $60 \mathrm{~min}$ of exercise (MS: $101 \pm 18$

305 bpm, $n=9 ; \mathrm{CON}(102 \pm 35$ bpm, $n=14 ; \mathrm{P}=0.91)$

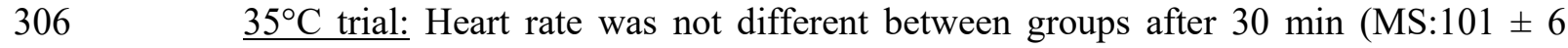

307 bpm, $n=7$; CON: $103 \pm 15 \mathrm{bpm}, n=8 ; \mathrm{P}=0.62)$ or 60 minutes of exercise (MS: $102 \pm 8$

308 bpm, $n=7$; CON: $101 \pm 23$ bpm, $n=8 ; \mathrm{P}=0.89)$.

309 Discussion

310 Our collaborative group has recently shown that compared to healthy controls, people

311 with MS demonstrate a blunted sudomotor, but not vasomotor response during moderate 
312 intensity exercise at a fixed metabolic $\mathrm{H}_{\text {prod }}\left(4.5 \mathrm{~W} \cdot \mathrm{kg}^{-1}\right)$ in a temperate climate $\left(25^{\circ} \mathrm{C}, 30 \%\right.$

$313 \mathrm{RH})(1)$. However, the blunted sweat response with MS was not large enough to alter the rise

314 in rectal and esophageal temperature in that study, possibly due to the relatively cool

315 conditions tested (1). The findings of the present study extend our previous investigations to

316 much hotter conditions (up to $\mathrm{T}_{\mathrm{a}}=35^{\circ} \mathrm{C}$ ). The ability of people with MS to complete exercise

317 at a fixed heat production in warm $\left(30^{\circ} \mathrm{C}, 30 \% \mathrm{RH}\right)$ or hot $\left(35^{\circ} \mathrm{C}, 30 \% \mathrm{RH}\right)$ environments in

318 this study was compromised compared to healthy controls. Furthermore, onset of sweating in

319 people with MS was delayed in both a warm $\left(30^{\circ} \mathrm{C}\right)$ and hot $\left(35^{\circ} \mathrm{C}\right)$ environment, however

320 decrements were only observed on the forearm, but not the upper back. Nevertheless, similar

321 rises in rectal temperature were observed between the MS and CON group throughout 60

322 minutes of exercise in both the WARM and HOT trials, showing that at high air

323 temperatures, thermoregulatory impairments in people with relapsing-remitting MS are not

324 sufficient to accelerate body heating during exercise. Even for those participants who could

325 not complete 60 minutes of exercise, the time required to reach a rise in rectal temperature of

$3260.2^{\circ} \mathrm{C}$, which is the theoretical lower limit at which Uhthoff's phenomenon is observed, was

327 the same compared to the CON participants in both the WARM and HOT trials. Taken

328 together, these findings suggest that temperature-induced MS symptoms (i.e., Uhthoff's

329 phenomenon) during exercise in warm and hot environments may occur prior to potential

330 impairments in thermoregulatory function in MS can be observed.

331 Previously our lab has demonstrated rectal temperature is not different between MS

332 and CON groups following $60 \mathrm{~min}$ of exercise in a thermoneutral $\left(25^{\circ} \mathrm{C}\right)$ environment (1).

333 However, despite participants exercising in a cooler environment than in the current study,

334 the rise in rectal temperature for the MS participants was greater $\left(\sim 0.8^{\circ} \mathrm{C}\right)$ in the

335 thermoneutral environment compared to the $30^{\circ} \mathrm{C}\left(\sim 0.45^{\circ} \mathrm{C}\right.$ rise in rectal temperature $)$ and

$33635^{\circ} \mathrm{C}\left(0.59^{\circ} \mathrm{C}\right.$ rise in rectal temperature $)$ environment. It is likely that the lower change in 
337 rectal temperature observed in the current study is due to the lower workload. It is possible 338 that a greater change in core temperature between the MS and CON groups may have been 339 observed if participants were working at a greater external workload. However, the fact that 340 even when working at $4 \mathrm{~W} \cdot \mathrm{kg}^{-1}$ over $40 \%$ of MS participants could not complete exercise in 341 the $30^{\circ} \mathrm{C}$ trial despite no difference in core temperature between groups, further confirms for 342 some people with MS, heat-related fatigue reflects an inherent sensitivity to smaller rises in 343 core temperature prior to any initiation of thermoregulatory response that may be impaired.

344 Sweat rates are predominantly determined by the amount of evaporation required to maintain 345 heat balance (6), which by design was fixed between the MS and CON groups in the present 346 study (Table 1). A rise in deep and peripheral tissue temperature during exercise in the heat 347 activates local temperature-sensitive neurons that relay afferent information to the preoptic 348 area of the anterior hypothalamus (33). Neuronal firing rates are subsequently altered to elicit 349 an efferent response such as an increase in sudomotor output. The present observation of a 350 delayed onset of sweating in the MS group indicates that pathophysiological events within 351 the CNS with MS may in some way impair this process. Indeed, it is known that injured 352 neurons cause a reduction in conduction velocity and depress the efficiency of a postsynaptic 353 response relative to a presynaptic stimulus (4,11, 15). Noronha (29) and Andersen (3) 354 reported qualitative evidence of sudomotor impairments in MS patients during a bout of 355 passive heating using the quinizarin powder test method. According to both studies $(3,29)$ 356 intravenous pilocarpine (a sympathetic cholinergic agonist) adequately increased whole body 357 sweating rate in patients who previously demonstrated a blunted sweating response to passive 358 heating. They postulated that a likely cause of sudomotor dysfunction for people with MS is 359 the damage to neurons within the descending sudomotor pathway. Despite a delayed onset of 360 sweating on the forearm, MS participants were still able to achieve the required steady state 361 sweat rate after 30 and 60 minutes of exercise which is consistent with previous work by our 
362 laboratory (1). As such, demyelination of neurons potentially only transiently weakens the

363 temporal sudomotor response to mild exercise in $30^{\circ} \mathrm{C}$ and $35^{\circ} \mathrm{C}$ environments.

364 It is widely acknowledged that local sweat rate can vary considerably across different

365 regions of the body in healthy individuals $(19,22,34)$, however, it is unclear why a delayed

366 onset of sweating was observed on the forearm only and not the upper back in people with

367 MS. Demyelination and scarring within the CNS is highly variable in terms of location and

368 severity (29). While we can only speculate, it is possible that a blunted sudomotor response

369 on the forearm is due to a) demyelination specific regions within the CNS and/or b) local

370 sweat gland atrophy. Although a delayed onset of sweating was observed on the forearm in

371 the MS compared to CON group, there were no differences in the onset of sweating between

372 the forearm and upper back within the MS group for both the WARM and HOT trial.

373 Therefore, these data may not necessarily indicate regional specificity in LSR differences in

374 people with MS. Notably, findings from our previous work regarding the LSR onset and

375 thermosensitivities are not consistent with the current study. For example, our previous work

376 demonstrated that LSR thermosensitivity was blunted in people with MS, whereas findings

377 from the current study demonstrate a delayed change in mean body temperature and onset

378 time for LSR, with no differences in thermosensitivities between the MS and CON

379 participants. This is possibly because in the current study, we investigated the onset and

380 thermosensitivities of individual sites (i.e. forearm and upper back) separately, whereas in our

381 previous work, LSR of the forearm and upper back were combined, potentially diluting any

382 regional-specific differences in sweating onset and thermosensitivities (1). Collectively, these

383 findings suggest that people with MS do demonstrate some sudomotor impairments,

384 however, due to the heterogeneity of MS, these impairments may present differently.

385 Nevertheless, irrespective of the underlying cause, MS participants were still able to achieve

386 similar steady state sweat rates compared to the CON group in both the current study and 
387 from our previous investigations (1). Given the rise in core temperature was similar between 388 MS and CON participants, any differences in evaporative heat loss due to a delayed onset of 389 sweating at the forearm seems to be minimal and/or possibly compensated for greater 390 sweating/evaporation at other body regions that were not measured.

391 In both the WARM and HOT trials, it was observed that only 9 out of 16 and 7 out of 3928 MS participants were able to complete 60 minutes of cycling, respectively. It has previously 393 been reported that people with MS have been unable to complete 60 min of exercise in a $39425^{\circ} \mathrm{C}(1)$ and $30^{\circ} \mathrm{C}(9)$ environment, possibly due to heat-related fatigue. All MS participants 395 stopped exercise due to volitional exhaustion. Although the reason for this exhaustion is 396 unclear, given the similar aerobic capacity between the MS $\left(2.4 \mathrm{~L} \cdot \mathrm{min}^{-1}\right)$ and $\mathrm{CON}(2.8$

$397 \mathrm{~L} \cdot \mathrm{min}^{-1}$ ) groups it is possible that the high dropout rate for the MS participants is the result of 398 a reduced exercise capacity due to heat sensitivity, independently of increases in core 399 temperature. For those who could not complete 60 minutes of cycling in both the WARM and 400 HOT trials, the final change in core temperature was within the threshold of Uhthoff's 401 phenomenon $\left(0.2-0.5^{\circ} \mathrm{C}\right)$, irrespective of exercise time (Figure 1 and 2$)$. However the time it 402 took to reach a rise in core temperature of $0.2^{\circ} \mathrm{C}$ was not different between the MS and CON 403 groups, nor was the final change in core temperature following 30 and 60 minutes of cycling 404 in both the WARM and HOT trials. Early research investigating Uhthoff's phenomenon ex 405 vivo and in animal models, suggested that increases in temperature of $\sim 0.5^{\circ} \mathrm{C}$ of a 406 demyelinated nerve reduces its conduction velocity by a greater amount compared to a 407 myelinated nerve (14) potentially contributing to heat-related symptoms. More recently, 408 White et al (38) reported an increase in core temperature of $0.6^{\circ} \mathrm{C}$ in people with MS reduced 409 conduction velocity, increased fatigue perception and impairments in force production to a 410 greater extent compared to healthy controls for the same rise in core temperature. On the 411 other hand, White et al (39) also demonstrated for the same rise in core temperature $\left(\sim 0.5^{\circ} \mathrm{C}\right)$ 
412 work output in people with MS was greater following a bout of whole-body cooling (baseline

413 core temperature $=36.4^{\circ} \mathrm{C}$ ) compared to no cooling (baseline temperature $=37.0^{\circ} \mathrm{C}$ ).

414 Furthermore, Chaseling et al (9) also demonstrated a 30\% increase in exercise time in people

415 with MS with ingestion of cold water $\left(1.5^{\circ} \mathrm{C}\right)$, despite no difference in the rise of core

416 temperature compared to ingestion of thermoneutral water $\left(37^{\circ} \mathrm{C}\right)$. Collectively these studies

417 suggest that a definitive rise in core temperature of $0.2-0.5^{\circ} \mathrm{C}$ may not exclusively influence

418 heat-related symptoms for people with MS, and perhaps anticipatory or psychological factors

419 may also play a role (24). For example, it is possible that some participants stopped exercise

420 prematurely in their first trial in anticipation of the onset of any heat-related symptoms,

421 which may explain why some MS participants were able to complete exercise in the HOT

422 compared to WARM trial. It is also possible given the heterogeneity of the disease (lesion

423 location and severity), some participants may be less sensitive to the heat which could

424 explain why some MS participants were able to complete 60 minutes of exercise while others

425 could not. Lastly, it is possible in the current study, people with MS stopped exercising at a 426 core temperature of $0.2-0.5^{\circ} \mathrm{C}$ due to a decreased conduction velocity, thereby increasing

427 perceptions of fatigue and reductions in force output. However, further research is warranted 428 to completely understand this.

\section{Limitations}

430 It is unclear if whole body sweat losses were different between the MS and CON 431 group as this was not measured in the present study. However, the primary concern for 432 people with MS during heat exposure is heat-related fatigue, which is presently believed to be 433 tied to the rise in core temperature (7). It follows that irrespective of whether whole-body 434 sweating was different in the MS group or not, any MS-related reductions in sudomotor 435 output due to a delayed onset of sweating were apparently insufficient to alter core 436 temperature. Measures of skin blood flow were not reported in this study, and therefore, it is 
unclear whether similarities in core temperature were due to differences in baseline skin blood flow as indicated by higher baseline skin temperature in the MS group. However it has previously been documented $(2,8)$ that people with MS do not demonstrate an impairment in vasomotor function. For example, Allen et al (2) reported differences in sweat output, but not cutaneous vascular conductance in MS compared to CON groups following a bout of whole

442 body heating in a $48^{\circ} \mathrm{C}$ water perfused suit. It therefore seems that pathways within the 443 sympathetic nervous system that are impacted by MS are restricted to the sudomotor 444 apparatus (20).

445 The sample size of this study is small because of the high rate of dropouts during 446 exercise within the MS group, which is an inherit limitation within the MS population. 447 Nevertheless, according to Cohen's $d$ (10) the magnitude of differences for the change in $T_{\text {re }}$ 448 in the $30^{\circ} \mathrm{C}(d=0.25)$ and $35^{\circ} \mathrm{C}(d=0.24)$ further demonstrate a small difference between 449 the MS and CON group means. Another possible limitation is the use of rectal instead of 450 esophageal temperature to assess thermoeffector control. Obtaining esophageal temperature 451 within this specific population proved difficult. Esophageal temperature measures were only 452 obtained in $8 \mathrm{MS}$ and $6 \mathrm{CON}$ participants in the $30^{\circ} \mathrm{C}$ trials and in no $\mathrm{MS}$ or $\mathrm{CON}$ 453 participants in the $35^{\circ} \mathrm{C}$ trials. As such, an insufficient number of esophageal temperature 454 values were attained to conduct an appropriately powered thermoeffector analysis. 455 Furthermore, while all 16 MS participants who participated in the WARM trial were invited 456 to return for the HOT trial, only 8 of these participants accepted. Only 5 of the 9 MS 457 participants who completed 60 minutes of exercise in the WARM trial returned to participate 458 in the HOT trials. While 1 participant was unable to complete 60 minutes of exercise in both 459 the WARM and HOT trials, 2 participants were able to complete 60 minutes of exercise in 460 the HOT but not the WARM trial. While it is possible that there was some self-selection bias 461 among the participants who participated in both the WARM and HOT trials, it is also 
462 possible that there was a learning effect given that all WARM trials were conducted before 463 the HOT trials.

464 Lastly, the results from this study are only limited to people with relapsing remitting 465 MS (RRMS). While people with RRMS make up for $80 \%$ of people diagnosed with MS, it is 466 unclear whether the results of the current study would translate to people with secondary 467 and/or primary progressive MS.

\section{Conclusion} warm $\left(30^{\circ} \mathrm{C}, 30 \% \mathrm{RH}\right)$ or hot $\left(35^{\circ} \mathrm{C}, 30 \% \mathrm{RH}\right)$ environment in this study was compromised compared to healthy controls despite similar increases in core temperature. Furthermore, despite a delayed onset of sweating on the forearm in the MS group, local sweat rates and the change in core temperature were similar between the MS and CON group. These findings suggest that temperature-induced MS symptoms (i.e. Uhthoff's phenomenon) that occur during exercise in warm and hot environments are not likely the result of a disproportionately greater rise in core temperature due to thermoregulatory impairments. Given these findings, future research should focus on practical and economical cooling strategies to overcome heatrelated fatigue and MS symptom onset during physical activity and/or heat exposure in warm and hot environments. Future research is also needed to identify whether these findings translate to people with a greater MS disease severity.

\section{Acknowledgements}

This study was supported by a Multiple Sclerosis Research Australia Project Grant 483 (Grant holders: Jay, Davis, Barnett; grant number \#17-227); and a Multiple Sclerosis 484 Research Australia Postgraduate Fellowship (Grant holders: Chaseling; grant number \#15485 087) and by an Australian Government Endeavour Post-Doctoral Research Fellowship (Grant 486 holder: Filingeri). 
488 Conflicts of Interest

The authors have no conflicts of interest to disclose. 
491 1.Allen DR, Huang M, Morris NB, Chaseling GK, Jay O, and Davis SL. Impaired

492 Thermoregulatory Function during Dynamic Exercise in Multiple Sclerosis. Medicine \&

493 Science in Sports \& Exercise 51: 395-404, 2018.

494 2.Allen DR, Huang M, Parupia IM, Dubelko AR, Frohman EM, and Davis SL. Impaired 495 sweating responses to a passive whole-body heat stress in individuals with multiple sclerosis. 496 Journal of Neurophysiology 118: 7-14, 2017.

497 3.Andersen EB, and Nordenbo AM. Sympathetic vasoconstrictor responses in multiple 498 sclerosis with thermoregulatory dysfunction. Clinical Autonomic Research 7: 13-16, 1997.

499 4.Armstrong LE, and Stoppani J. Central nervous system control of heat acclimation 500 adaptations: an emerging paradigm. Reviews in the Neurosciences 13: 271-285, 2002.

501 5.Astrand P, and Rodahl K. Evaluation of physical work capacity on the basis of tests. In:

502 Textbook of Work Physiology: Physiological Basis of Exercise. Champaign (IL): 1977, p.

503 333-365.

504 6.Bain AR, Deren TM, and Jay O. Describing individual variation in local sweating during 505 exercise in a temperate environment. European Journal of Applied Physiology 111: 1599-

$506 \quad 1607,2011$.

507 7.Bol Y, Smolders J, Duits A, Lange IMJ, Romberg - Camps M, and Hupperts R.

508 Fatigue and heat sensitivity in patients with multiple sclerosis. Acta Neurologica

509 Scandinavica 126: 384-389, 2012.

510 8.Cartlidge NE. Autonomic function in multiple sclerosis. Brain 95: 661-664, 1972.

511 9.Chaseling GK, Filingeri D, Barnett M, Hoang P, Davis SL, and Jay O. Cold water 512 ingestion improves exercise tolerance of heat-sensitive people with MS. Medicine \& Science 513 in Sports \& Exercise 50: 643-648, 2018.

514 10.Cohen J. Statistical power analysis for the behavioral sciences. 2nd. Hillsdale, NJ:

515 erlbaum, 1988.

516 11.Conte A, Li Voti P, Pontecorvo S, Quartuccio ME, Baione V, Rocchi L, Cortese A, 517 Bologna M, Francia A, and Berardelli A. Attention-related changes in short-term cortical 518 plasticity help to explain fatigue in multiple sclerosis. Multiple Sclerosis Journal 22: 1359519 1366, 2016.

520 12.Cramer MN, and Jay O. Partitional calorimetry. Journal of Applied Physiology 126: $521 \quad 267-277,2018$.

522 13.Cramer MN, and Jay O. Selecting the correct exercise intensity for unbiased 523 comparisons of thermoregulatory responses between groups of different mass and surface 524 area. Journal of Applied Physiology 116: 1123-1132, 2014. 
14.Davis FA, and Jacobson S. Altered thermal sensitivity in injured and demyelinated nerve

526 A possible model of temperature effects in multiple sclerosis. Journal of Neurology,

527 Neurosurgery \& Psychiatry 34: 551-561, 1971.

528 15.Davis SL, Wilson TE, Vener JM, Crandall CG, Petajan JH, and White AT.

529 Pilocarpine-induced sweat gland function in individuals with multiple sclerosis. Journal of

$530 \quad$ Applied Physiology 98: 1740-1744, 2005.

531 16.Fitchett M. Predictability of VO2 max from submaximal cycle ergometer and bench

532 stepping tests. British Journal of Sports Medicine 19: 85-88, 1985.

533 17.Frohman TC, Davis SL, Beh S, Greenberg BM, Remington G, and Frohman EM.

534 Uhthoff's phenomena in MS - clinical features and pathophysiology. Nature Reviews

535 Neurology 9: 535-540, 2013.

536 18.Gisolfi CV, and Wenger CB. Temperature regulation during exercise: old concepts, new

537 ideas. Exercise and Sport Sciences Reviews 12: 399-416, 1984.

538 19.Inoue Y, Nakao M, Araki T, and Murakami H. Regional differences in the sweating

539 responses of older and younger men. Journal of Applied Physiology 71: 2453-2459, 1991.

540 20.Jänig W, and McLachlan EM. Characteristics of function-specific pathways in the

541 sympathetic nervous system. Trends in Neurosciences 15: 475-481, 1992.

542 21.Jay O, Bain AR, Deren TM, Sacheli M, and Cramer MN. Large differences in peak

543 oxygen uptake do not independently alter changes in core temperature and sweating during

544 exercise. American Journal of Physiology - Regulatory, Integrative and Comparative

545 Physiology 301: R832-R841, 2011.

546 22.Kondo, Takano, Aoki, Shibasaki, Tominaga, Inoue, and Kondo N. Regional

547 differences in the effect of exercise intensity on thermoregulatory sweating and cutaneous

548 vasodilation. Acta Physiologica Scandinavica 164: 71-78, 1998.

549 23.Lee J-Y, Wakabayashi H, Wijayanto T, and Tochihara Y. Differences in rectal

550 temperatures measured at depths of 4-19 $\mathrm{cm}$ from the anal sphincter during exercise and rest.

551 European Journal of Applied Physiology 109: 73-80, 2010.

552 24.Marino FE. Heat reactions in multiple sclerosis: an overlooked paradigm in the study of

553 comparative fatigue. International Journal of Hyperthermia 25: 34-40, 2009.

554 25.Maritz J, Morrison J, Peter J, Strydom N, and Wyndham C. A practical method of

555 estimating an individual's maximal oxygen intake. Ergonomics 4: 97-122, 1961.

556 26.Mekjavic IB, and Eiken O. Contribution of thermal and nonthermal factors to the

557 regulation of body temperature in humans. Journal of Applied Physiology 100: 2065-2072,

5582006.

559 27.Nadel ER, Bullard RW, and Stolwijk J. Importance of skin temperature in the

560 regulation of sweating. Journal of Applied Physiology 31: 80-87, 1971.

561 28.Nishi Y. Measurement of thermal balance in man. Bioengineering, Thermal Physiology

562 and Comfort 29-39, 1981. 
29.Noronha M, Vas C, and Aziz H. Autonomic dysfunction (sweating responses) in

564 multiple sclerosis. Journal of Neurology, Neurosurgery, and Psychiatry 31: 19-22, 1968.

565 30.Poh PY, Adams AN, Huang M, Allen DR, Davis SL, Tseng AS, and Crandall CG.

566 Increased postural sway in persons with multiple sclerosis during short-term exposure to

567 warm ambient temperatures. Gait \& Posture 53: 230-235, 2017.

568 31.Ramanathan $\mathbf{N}$. A new weighting system for mean surface temperature of the human 569 body. Journal of Applied Physiology 19: 531-533, 1964.

570 32.Rasminsky M. The effects of temperature on conduction in demyelinated single nerve 571 fibers. Archives of Neurology 28: 287-292, 1973.

572 33.Shibasaki M, Wilson TE, and Crandall CG. Neural control and mechanisms of eccrine 573 sweating during heat stress and exercise. Journal of Applied Physiology 100: 1692-1701, 5742006.

575 34.Smith CJ, and Havenith G. Body mapping of sweating patterns in male athletes in mild 576 exercise-induced hyperthermia. European Journal of Applied Physiology 111: 1391-1404, 5772011.

578 35.Summers MP, Simmons RD, and Verikios G. Keeping cool: Use of air conditioning by 579 Australians with multiple sclerosis. Multiple Sclerosis International 2012: 1-6, 2012.

580 36.Syndulko K, Jafari M, Woldanski A, Baumhefner RW, and Tourtellotte WW. Effects 581 of temperature in multiple sclerosis: a review of the literature. Journal of Neurologic 582 Rehabilitation 10: 23-34, 1996.

583 37.Uhthoff W. Studies on the occurring in multiple sclerosis stove eye disorders. Arch. f. 584 Psychiatrie u. Nervenheilk Bd XXI 1889.

585 38. White AT, VanHaitsma TA, Vener J, and Davis SL. Effect of passive whole body 586 heating on central conduction and cortical excitability in multiple sclerosis patients and 587 healthy controls. Journal of Applied Physiology 114: 1697-1704, 2013.

588 39. White AT, Wilson TE, Davis SL, and Petajan JH. Effect of precooling on physical 589 performance in multiple sclerosis. Multiple Sclerosis Journal 6: 176-180, 2000. 
592 Figure 1A-E. The upper panel shows individual values for the change in rectal (A) and skin

593 (B) temperature for the MS (dark grey circles) and CON (light grey circles) group following 59430 (MS: $n=14$; CON: $n=14$ ) and 60 (MS: $n=9$; CON: $n=14$ ) minutes of exercise in the 595 WARM trial. The lower panel shows the time taken to reach a rise in rectal temperature of $5960.2^{\circ} \mathrm{C}(\mathbf{C})$ in the WARM trial for the MS (dark grey circles) and CON (light grey circles). 597 The change in rectal temperature at the end of exercise in the WARM trial for MS group who 598 completed exercise (D; dark grey circles), who could not complete 60 minutes of exercise 599 (white circles) and for the CON group (E; light grey circles), all of which completed 60 600 minutes of exercise. The grey shading on panel $\mathrm{D}$ demonstrates the change in rectal 601 temperature at which Uhthoffs phenomenon is reportedly induced (17).

602 Figure 2 A-E. The upper panel shows individual values for the change in rectal (A) and skin

603 (B) temperature for the MS (white diamonds) and CON (black diamonds) group following 30

604 (MS: $n=7$;ON: $n=8)$ and 60 (MS: $n=7$; CON: $n=8)$ minutes of exercise in the HOT

605 trial. The lower panel shows the time taken to reach a rise in rectal temperature of $0.2{ }^{\circ} \mathrm{C}(\mathbf{C})$

606 in the HOT trial for the MS (black diamonds) and CON (white diamonds). The change in

607 rectal temperature at the end of exercise in the HOT trial for MS group who completed

608 exercise (D; black diamonds), who could not complete 60 minutes of exercise (D; light grey

609 diamond) and for the CON group (E; white diamonds), all of who completed 60 minutes of

610 exercise. The grey shading on panel D demonstrates the change in rectal temperature at

611 which Uhthoffs phenomenon is reportedly induced (17).

612 Figure 3A-D. Mean and 95\% confidence intervals for the change in mean body temperature 613 in the WARM trial (circles) plotted against the rise in upper back (A) and forearm (B) local 614 sweat rate (LSR) during the and HOT trial (diamonds) fir the upper back (C) and forearm 615 (D). Asterisk denotes $\mathrm{P}<0.05$. 

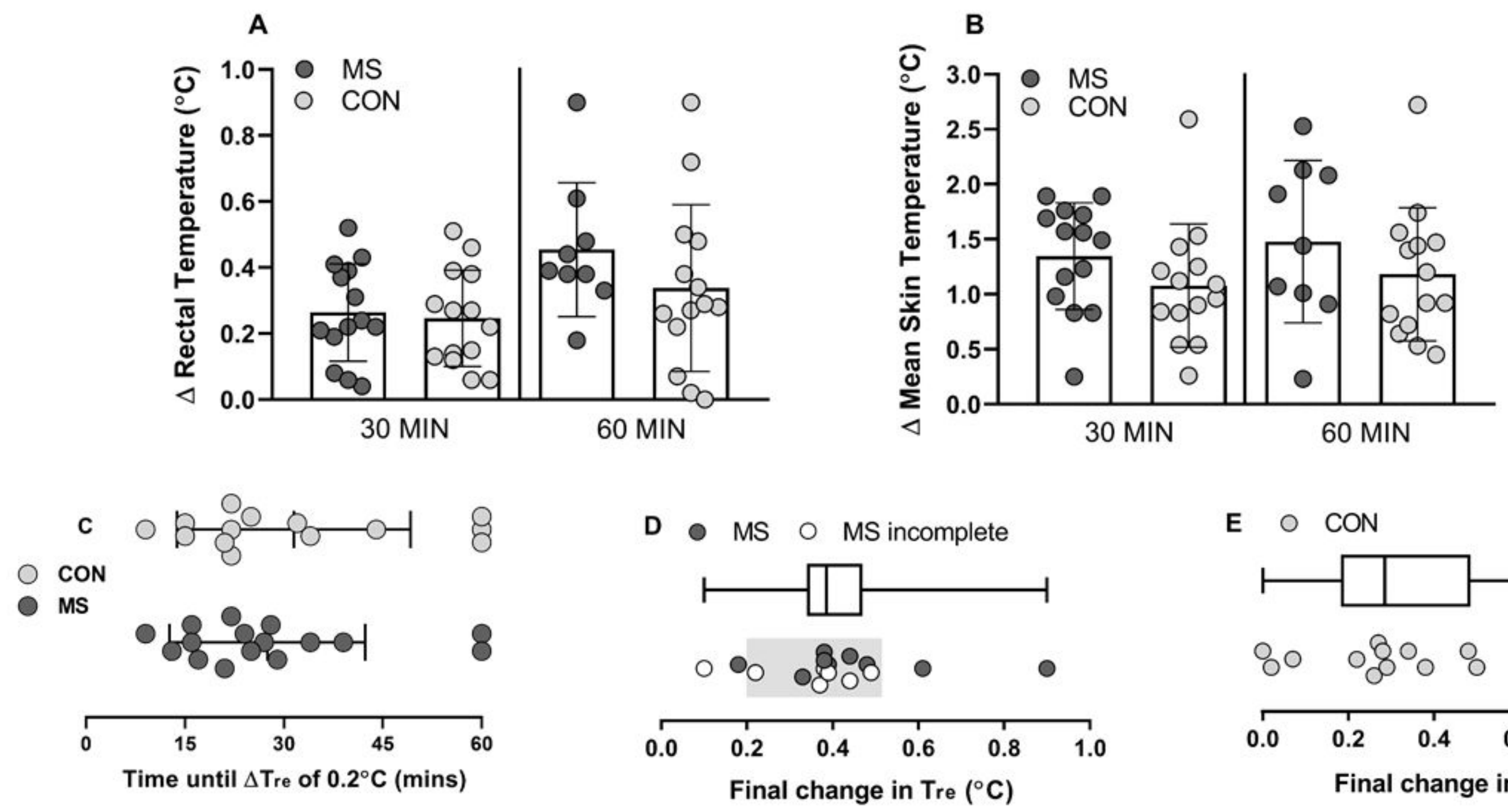

E $O \mathrm{CON}$

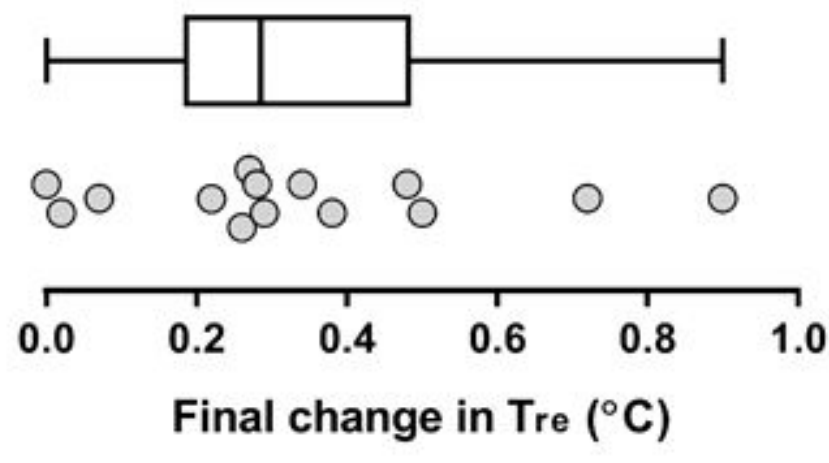



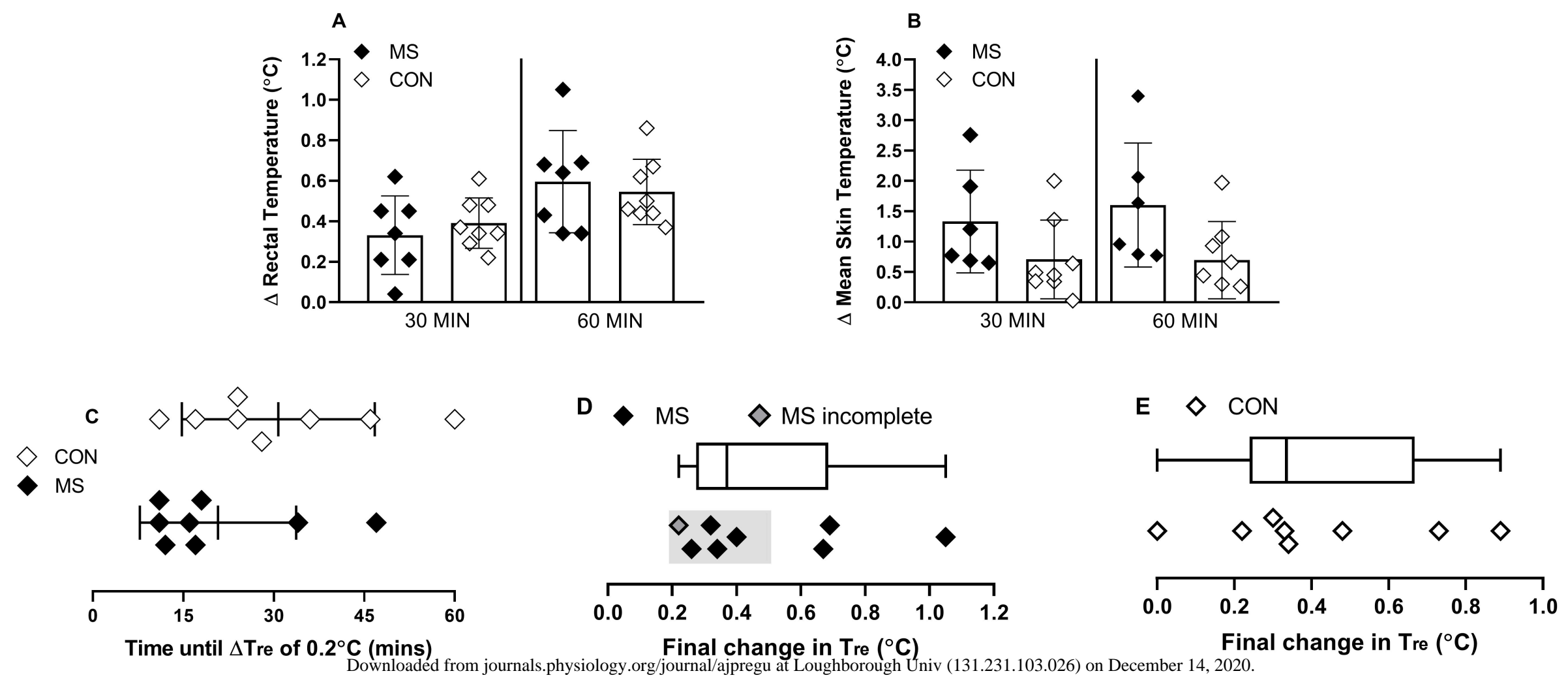


\section{$30^{\circ} \mathrm{C}$ Trial}
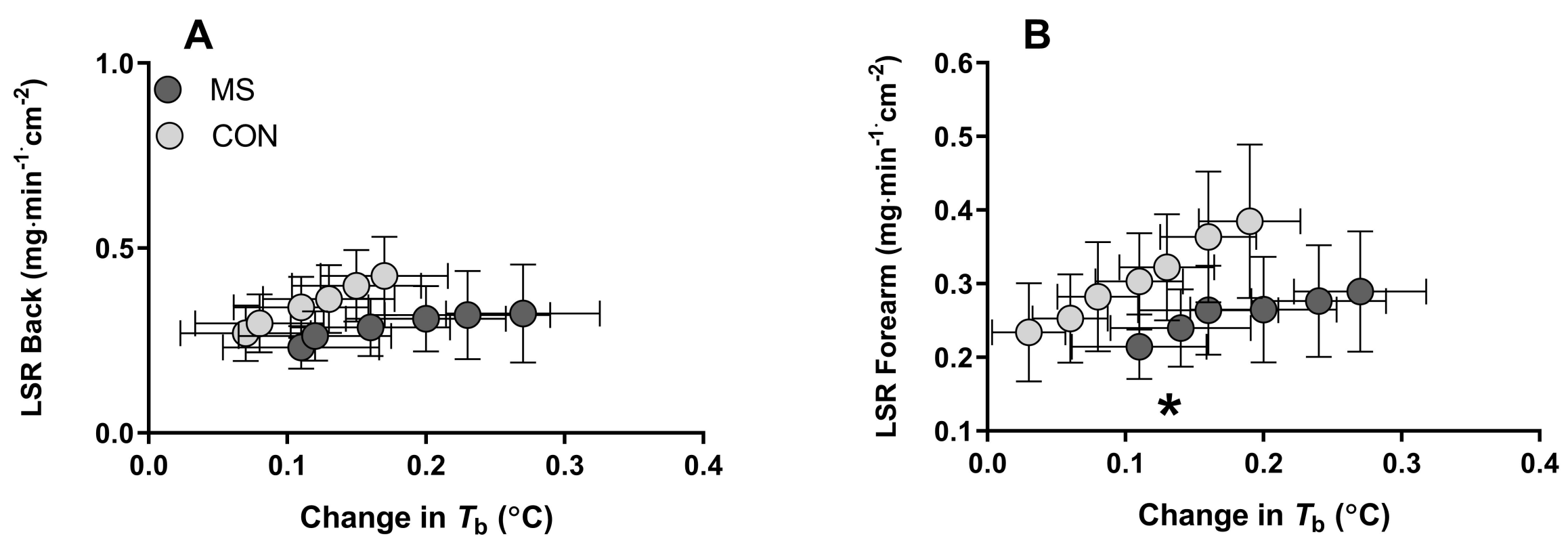

$35^{\circ} \mathrm{C}$ Trial
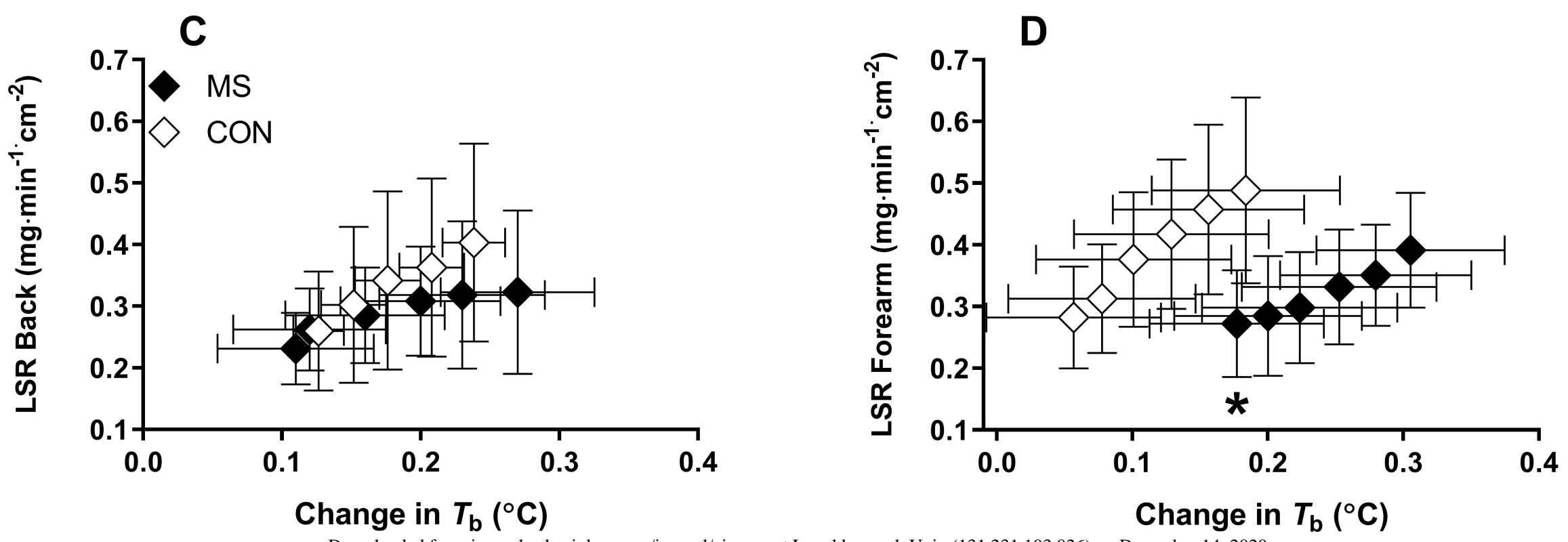

Downloaded from journals.physiology.org/journal/ajpregu at Loughborough Univ (131.231.103.026) on December 14, 2020. 
Table 1. Participant characteristics and workloads

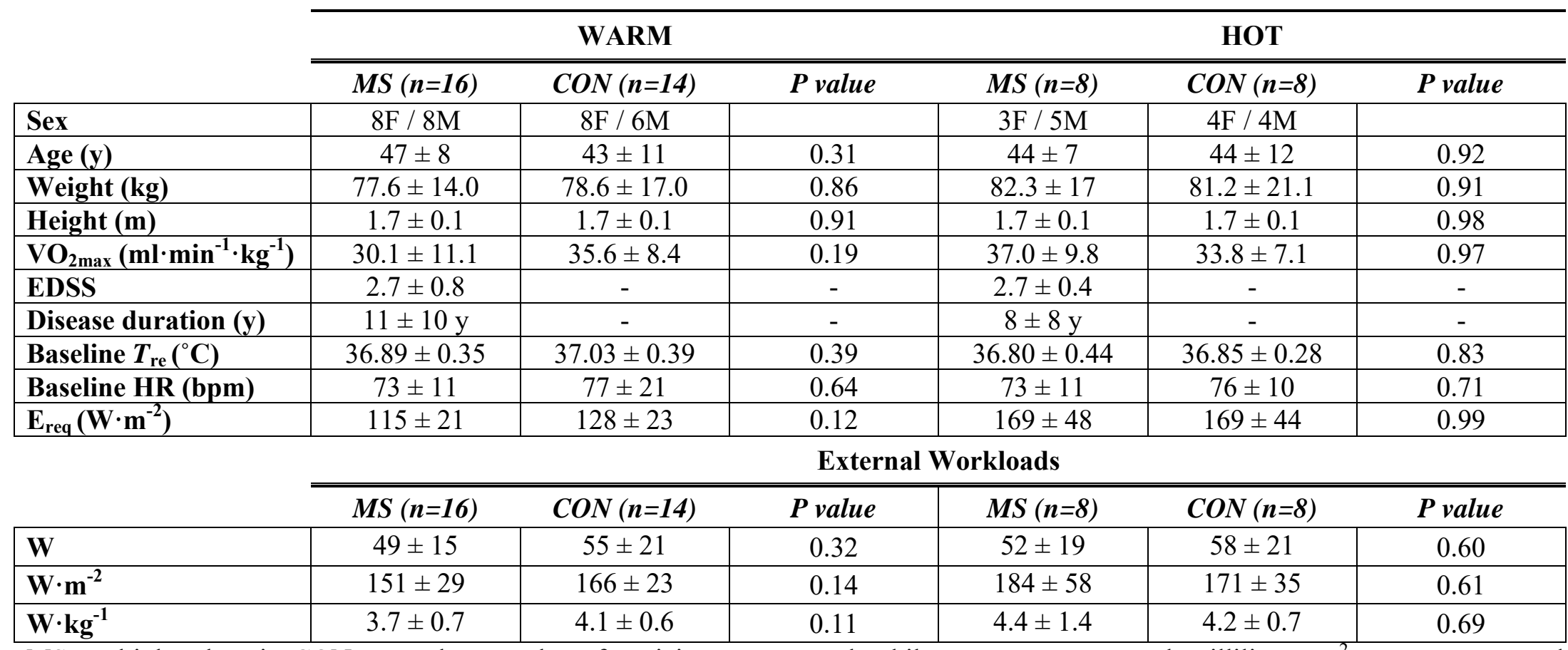

MS: multiple sclerosis; CON: control; $n$ : number of participants; y: year; kg: kilograms; m: meters; ml: millilitres; $\mathrm{m}^{-2}$ : per meter squared; $T_{\text {re: }}$ rectal temperature; HR: heart rate; $\mathrm{E}_{\text {req }}$ : evaporative requirement 
Table 2. Sweat rates for the MS and CON groups in both the WARM and HOT trials.

\begin{tabular}{|c|c|c|c|c|c|c|}
\hline \multirow{3}{*}{ Forearm } & \multirow{2}{*}{\multicolumn{2}{|c|}{ WARM }} & & & & \\
\hline & & & \multirow[b]{2}{*}{$\begin{array}{c}P \\
\text { value }\end{array}$} & \multicolumn{2}{|c|}{ HOT } & \multirow[b]{2}{*}{$\begin{array}{c}P \\
\text { value }\end{array}$} \\
\hline & MS & $C O N$ & & MS & CON & \\
\hline 30-min LSR $\left(\mathrm{mg} \cdot \mathrm{min}^{-1} \cdot \mathrm{cm}^{-2}\right)$ & $0.35 \pm 0.18(n=14)$ & $0.44 \pm 0.19(n=14)$ & 0.19 & $0.50 \pm 0.15(n=6)$ & $0.68 \pm 0.16(n=8)$ & 0.06 \\
\hline 60-min LSR $\left(\mathrm{mg} \cdot \mathrm{min}^{-1} \cdot \mathrm{cm}^{-2}\right)$ & $0.45 \pm 0.17(n=9)$ & $0.48 \pm 0.18(n=14)$ & 0.69 & $0.55 \pm 0.11(n=6)$ & $0.68 \pm 0.13(n=8)$ & 0.08 \\
\hline \multicolumn{7}{|l|}{ Upper back } \\
\hline 30-min LSR $\left(\mathrm{mg} \cdot \mathrm{min}^{-1} \cdot \mathrm{cm}^{-2}\right)$ & $0.38 \pm 0.29(n=13)$ & $0.48 \pm 0.27(n=14)$ & 0.32 & $0.63 \pm 0.33(n=6)$ & $0.58 \pm 0.25(n=8)$ & 0.78 \\
\hline 60-min LSR $\left(\mathrm{mg} \cdot \mathrm{min}^{-1} \cdot \mathrm{cm}^{-2}\right)$ & $0.47 \pm 0.32(n=8)$ & $0.55 \pm 0.25(n=14)$ & 0.54 & $0.72 \pm 0.35(n=6)$ & $0.64 \pm 0.24(n=8)$ & 0.59 \\
\hline
\end{tabular}

MS: multiple sclerosis; CON: control; $n$ : number of participants; LSR: local sweat rate; mg: milligrams; $\mathrm{m}^{-2}$ : per meter squared. 